\title{
ENFERMAGEM À MULHER EM TRATAMENTO QUIMIOTERÁPICO - UMA ANÁLISE COMPREENSIVA DO ASSISTIR
}

\author{
NURSING FOR WOMEN UNDER CHEMOTHERAPY TREATMENT - A CARE \\ COMPREHENSIVE ANALYSIS \\ ENFERMERÍA A LA MUJER EN TRATAMIENTO QUIMIOTERÁPICO - UN ANÁLISIS \\ COMPRENSINO DEL ASISTIR
}

\section{Teresa Caldas Camargo ${ }^{1}$ \\ Ivis Emilia de Oliveira Souza ${ }^{2}$}

\begin{abstract}
RESUMO: Este estudo surgiu a partir de minhas reflexões como enfermeira da Central de Quimioterapia do Hospital Luiza Gomes de Lemos, do Instituto Nacional de Câncer (Inca), e como aluna do curso de mestrado da Escola de Enfermagem Anna Nery-UFRJ. Estar elaborando a dissertação de mestrado utilizando o referencial filosófico de Martin Heidegger, possibilitou-me refletir sobre o agir profissional da equipe de enfermagem, mediada pelo pensamento deste filósofo. Nesta pesquisa, observei situações do meu dia-a-dia e registrei-as refletindo sobre aproximaçōes e distanciamentos da assistência de enfermagem no cenário acima descrito, com o intuito de analisá-las à luz do pensamento heideggeriano.Tratou-se também de uma reflexão sobre questões emergentes do processo de pesquisar e da prática de assistir que pôde propiciar um outro saber para a assistência de enfermagem à mulher em tratamento quimioterápico. Pude, assim, vislumbrar a assistência de enfermagem por uma outra ótica, aquela da compreensão como possibilidade do agir profissional.
\end{abstract}

PALAVRAS-CHAVE: Quimioterapia antineoplásica - Cuidados de enfermagem Método heideggeriano.

ABSTRACT: This study was developed upon my reflections as a nurse working at the Antineoplastic Chemotherapy Center at Luiza Gomes de Lemos Hospital of the National Cancer Institute (Inca), and as a Master course student at Anna Nery Nursing School. Developing my Master thesis on Martin Heidegger's philosophical thinking it has enabled me to reflect about the nursing care, considering this philosopher's thinking. In this study, I have registered some situations that occurred on my working days, in the scenary mentioned above, and reflected about them. seeking to analyse their proximity and distance from Heidegger's philosophical thinking. This study was also a reflection about questions emerging from the research process and care practice which leaded me to another understanding of nursing care to women who are submitted to chemotherapy treatment. Then, I was able to see nursing care in another way, that one of comprehension as a possibility of professional action.

KEYWORDS: Antineoplastic agents - Nursing care - Heideggerian method.

1 Enfermeira do Hospital Luiza Gomes de Lemos, unidade hospitalar III do Instituto Nacional de Câncer. Mestre em Enfermagem. Doutoranda da Escola de Enfermagem Anna Nery/ UFRJ.

${ }^{2}$ Professora Adjunta Doutora do Departamento de Enfermagem Materno-Infantil da Escola de Enfermagem Anna Nery/ UFRJ. Coordenadora Geral de Pós-graduação e Pesquisa da EEAN/UFRJ. Orientadora da Dissertação. 
RESUMEN: Este estudio nació a partir de mis reflexiones como enfermera de la Central de Quimioterapia del Hospital Luiza Gómes de Lemos, del Instituto Nacional de Cáncer (Inca), y como alumna del curso de maestrado de la Escuela de Enfermeria Anna Nery - UFRJ. Estar preparando la disertación de maestrado usando el referencial filosófico de Martin Heidegger, me posibilitó reflexionar sobre el actuar profesional del equipo de enfermeria, intermediada por el pensamiento de este filósofo. En esta pesquisa, observé situaciones de mi día a día y las registré reflexionando sobre aproximaciones y distanciamentos de la asistencia de enfermería en el escenario descrito anteriormente, con el propósito de analizarlas a la luz del pensamiento heideggeriano. También se trató de una reflexión sobre cuestiones emergentes del proceso de pesquisar y de la práctica de asistir que puede dar un outro saber para la asistencia de enfermeria a la mujer en tratamiento quimioterápico. Pude, de esta forma, vistumbrar la asistencia de enfermería por una outra óptica, aquella de la comprensión como posibilidad del actuar profesional.

PALABRAS CLAVE: Quimioterapia antineoplásica - Cuidados de enfermería Método heideggeriano.

\section{INTRODUÇÃO}

Este estudo surgiu a partir de minhas reflexões como enfermeira da Central de Quimioterapia do Hospital Luiza Gomes de Lemos, unidade hospitalar III do Instituto Nacional de Câncer(Inca) e como aluna do curso de mestrado da Escola de Enfermagem Anna Nery -UFRJ. Estar elaborando a dissertação de mestrado utilizando o referencial filosófico de Martin Heidegger e continuando ao mesmo tempo minha atividade assistencial, possibilitou-me refletir sobre $\circ$ agir profissional da equipe de enfermagem, mediada pelo pensamento deste filósofo.

A Central de Quimioterapia funciona diariamente no periodo da manhã e conta em média com duas enfermeiras e duas auxiliares de enfermagem. São realizadas em média, por dia, 20 quimioterapias, sendo a maioria da clientela mulheres portadoras de câncer de mama.

$\mathrm{Na}$ primeira vez que comparece para tratamento, a mulher é orientada pela enfermeira sobre como agem os quimioterápicos, seus efeitos colaterais e como podem ser amenizados, sinais e sintomas que devem ser comunicados ao médico durante o período de tratamento e necessidades nutricionais. $\dot{E}$ assegurado também à mulher que, havendo qualquer dúvida ou problema durante o tratamento, ela pode recorrer à equipe de enfermagem para auxiliá-la.

A equipe de enfermagem esforça-se por manter o ambiente agradável $e$ descontraido, pois entende ser este um tratamento dificil tanto física quanto psicologicamente. No entanto, a pressäo para o cumprimento de rotinas, o grande número de mulheres agendadas para o tratamento diário e o número insuficiente de pessoal torna o assistir muito corrido e dificil para se ter tempo de realmente estar junto a cada uma daquelas mulheres em sua peculiaridade $e$ singularidade. 
Por vezes, me parece que o trabalho está se desenvolvendo numa ação mecânica onde o importante é cumprir a meta daquele dia. Assim, se a rede venosa das mulheres naquele dia está muito dificil, se há um número razoável de clientes nervosas ou chorosas ou deprimidas, tudo isso torna a meta a ser cumprida mais dolorosa e desgastante para a equipe. Não são incomuns os comentários como: "Hoje está terrivel!", "Aquela paciente está muito nervosa, não consigo pegar a veia!", "É melhor encaminhar para a psicóloga!"

O cansaço muitas vezes toma conta da equipe. $\mathrm{E}$ a pressão do tempo que deve ser gasto na atividade, o cuidado no manuseio e administração do quimioterápico, parecem prevalecer sobre a própria cliente, que, como ser singular que é, está ali num momento no mínimo difícil de sua existência.

Ao trilhar o caminho da Fenomenologia enquanto método por mim utilizado na dissertação de mestrado, pude lançar um outro olhar para a minha atividade diária e perceber o quão pouco o outro, em sua singularidade, tem sido privilegiado. O relacionamento profissional enfermeiro/cliente, mediado pela empatia, que, segundo Boemer (1984:27), significa sentir com o outro o que ele sente mas sem com isso estar vivenciando o mesmo que ele, não tem sido exercitado pela correria do dia a dia.

Penso que o método científico, que não privilegia o outro enquanto pessoa, que quer apenas resultados e comprovações dos achados, tem sido a tônica na formação profissional do enfermeiro, a qual, pautada no modelo biomédico, tem valorizado as patologias, as técnicas, a administração dos serviços, as rotinas e o cumprimento da carga horária semanal em detrimento da pessoa doente.

Assim, estando voltada para o pensamento heideggeriano, observei situaçōes do meu dia-a-dia e registrei-as, procurando aproximações e distanciamentos da assistência de enfermagem diária no cenário acima descrito com este pensar, com o intuito analisá-las à luz deste referencial filosófico.

Este estudo intenciona compreender o fazer do profissional no seu dia-a-dia, valorizando a possibilidade de mostrar que um outro olhar pode alterar a atividade rotineira e com ele humanizar a assistência de enfermagem, que pretende ser holística. Trata-se também de uma reflexão sobre questões emergentes do processo de pesquisar e da prática de assistir que pode propiciar um outro saber para a assistência de enfermagem à mulher em tratamento quimioterápico.

\section{OBJETO DO ESTUDO}

Situações assistenciais de enfermagem no dia-a-dia da Central de Quimioterapia do Hospital Luiza Gomes de Lemos 


\section{OBJETIVO DO ESTUDO}

Compreender o fazer profissional no seu dia-a-dia, buscando analisar as aproximações e distanciamentos à ótica do pensamento heideggeriano.

\section{TRAJETÓRIA DO ESTUDO E METODOLOGIA}

Estando voltada para a Fenomenologia enquanto método por mim utilizado na dissertação de mestrado e o pensamento heideggeriano, passei a refletir sobre as situações assistenciais por mim vivenciadas em meu cotidiano profissional, com o olhar diferente que a abordagem fenomenológica possibilita, ao buscar a compreensão do humano em seu cotidiano.

Assim, entendendo a enfermagem como uma assistência que se dá ao outro, numa relação entre pessoas, pude perceber que a abordagem fenomenológica pode mediar a interação tão necessária ao prestar cuidado ao meu semelhante.

Ao aproximar-me da Fenomenologia, pude vislumbrar um meio de chegar à compreensão do comportamento assumido pela equipe de enfermagem na sua atividade diária, considerando o em si mesmo do fenômeno assistir e, a partir daí, lançar um outro olhar à prática de cuidar, que possibilita eliminar o vazio trazido pelas formas explicativas da tradição, que, preocupada com quantitativos e rotinas, não valoriza questões relativas aos sentimentos humanos.

Passei, portanto, a observar, com olhar atentivo, situações do dia-a-dia da assistência de enfermagem na Central de Quimioterapia. Este olhar, foi possibilitando-me cada vez mais perceber inúmeras situações ocorridas no meu cotidiano assistencial, e que me levaram a questionar o assistir à cliente.

A formalidade no atendimento, que enfoca a quimioterapia e seus efeitos colaterais, psicológicos e sociais apenas como fatos, levaram-me a refletir sobre o fazer profissional na maioria das vezes está fechado para sua possibilidade originária de ser-no-mundo-com ${ }^{3}$.

As situações observadas foram registradas num diário de campo, com a intenção de descrevê-las e não de explicá-las ou buscar suas relações de causa pois a preocupação em fenomenologia é mostrar e não demonstrar, permitindo que, através de uma descrição rigorosa, se chegue à essência do fenômeno, o qual se mostra a partir de si mesmo.

Após a descrição das situações vivenciadas, procedi à leitura individual de cada uma, selecionando quatro delas, as quais procuro, neste estudo, analisar compreensivamente apoiada pelo pensamento heideggeriano.

${ }^{3}$ As palavras em itálico que aparecem no texto denotam o pensar de Martin Heidegger. 


\section{Situação número 1}

A enfermeira M. prepara-se para puncionar a veia da paciente S. A rede venosa está difícil, as veias muito finas, pouco calibrosas. A pele está algo desidratada na avaliação da enfermeira e ela diz à paciente:

M. - A senhora não está tomando liquidos, por isso está dificil conseguir uma veia!

S.-Tomo líquido sim!

M.-Mas năo o bastante...

S.-Tomo sim, mais de 4 litros por dia...

Ao conseguir a veia e puncioná-la, a enfermeira replica:

M. - Tanto não toma que o sangue está grosso e escuro. Isso significa que a senhora não está tomando liquidos.

S.-Mas eu tomo...

O momento da punção venosa é tenso para a paciente e para o profissional. A paciente sente dor e o profissional sente-se mal por infligir dor e não querer errar.

No caso descrito, a enfermeira acaba por colocar a responsabilidade da rede venosa dificil na paciente. Ela esquece que só o líquido não basta para manter a rede venosa em boas condiçōes. A própria quimioterapia danifica a rede venosa. Mesmo assim, deve recomendar a ingesta hidrica aumentada, porém não há necessidade de entrar em atrito com a paciente.

Não seria melhor comentar com ela que a rede venosa estava dificil, sua pele desidratada e que ela deveria tomar ainda mais liquidos do que costuma tomar? E explicar a importância do liquido mais uma vez, acrescentando que o quimioterápico ao agir danifica as veias?

Olhar a paciente como um ser singular que necessita de nosso apoio e palavra facilitam o trabalho do profissional. Estabelecer uma relação amigável, sem imposiçōes do saber científico, torna nosso dia-a-dia mais produtivo, menos cansativo e nos permite o encontro com o outro que ali está temeroso com sua situaçäo.

A enfermeira está aqui ocupando-se do ente veia, não se preocupa com o ser singular que cada um de nós é. Ao contrário, lida com o outro no modo da ocupação.

Ser-no-mundo é essencialmente ser-com e o mundo é sempre mundo compartilhado. No pensar de Heidegger, o ser-com, enquanto característica existencial da pre-sença, deve se exprimir na convivência através de um preocupar-se com o outro e um ocupar-se das coisas. 
O se ocupar não é uma característica ontológica do ser-com, mas sim um modo de ser da pre-sença para com os entes que vêm ao encontro no mundo como ocupação.

Sobre isso Heidegger (1995:173) nos diz que

$O$ ente com o qual a pre-sença se comporta como ser-com, também não possui o modo de ser do instrumento à mão, pois ele mesmo é pre-sença. Desse ente não se ocupa, com ele se preocupa.

A preocupação é uma característica ontológica da pre-sença enquanto sercom. Porém, cotidianamente e na maior parte das vezes nos encontramos nas formas deficientes da preocupação, caracterizada pela indiferença. Assim, na convivência cotidiana agimos na maioria das vezes ocupando-nos do ser como a um manual, e desta forma entificando-o.

Ser-com o outro é ser co-presença origináriamente, e não lidar com o outro como coisas simplesmente dadas no mundo. E sobre isso Heidegger (1995 :178) diz:

.. Na medida em que a pre-sença é, ela possui o modo de ser da convivência. Esta não pode ser concebida como o resultado da soma de vários "sujeitos". $O$ deparar-se com o contingente numérico de "sujeitos só é possível quando os outros são tratados como "números". Tal contingente só se descobre por meio de um determinado ser-com e para os outros.Esse ser-com "desconsiderado" "computa" os outros sem "levá-los em conta" seriamente, sem querer "ter algo a ver" com eles.

Estando ocupada com a paciente e com o ente veia, a enfermeira está fechada em seu ser para a co-presença do outro. Porém, sendo em seu ser com, a pre-sença já tem uma compreensão do outro, pois ao ser-com também pertence a abertura da co-presença dos outros. A compreensão do outro é um modo de ser existencial e originário, e não significa apenas tomar conhecimento, reconhecer algo. Mas sim funda-se no compreender originário do ser-com, e sobre esta compreensão Heidegger (1995 :176) comenta:

Este conhecer-se está fundado no ser-com que compreende origináriamente. Ele se move, de início, segundo o modo de ser mais imediato do ser-no-mundo que é com, no conhecimento compreensivo do que a pre-sença encontra e do que ela se ocupa na circunvisão do mundo circundante. A partir da ocupação e do que nela se compreende é que se pode entender a ocupação da preocupação. $O$ outro se descobre, assim, antes de tudo, na preocupação das ocupações. 


\section{Situação número 2}

A equipe trabalha febrilmente. São muitas pacientes hoje, uma terça-feira, e o tempo é contado no relógio, pois, ao finalizar o horário de funcionamento da Central de Quimioterapia na parte da manhä, as enfermeiras e as auxiliares de enfermagem têm que almoçar e realizar outra atividade no periodo da tarde no ambulatório, que são, para as enfermeiras, os curativos externos que diáriamente estão agendados e têm sido em média de 20 por tarde; já as auxiliares de enfermagem estão escaladas em sala de consulta para acompanhar e auxiliar o atendimento médico.

A pressão ocorre assim e, além do fazer após o turno da manhã, a equipe também está muito concentrada com o fazer na Central de Quimioterapia que envolve a punção venosa, diluição de medicação, fluxo de entrada e saída das pacientes, observação da paciente durante o tratamento, anotação de possiveis intercorrências, etc.

As pacientes entram, fazem o tratamento e saem, uma após a outra. Quase não há conversa entre as mulheres e a equipe de enfermagem.

A manhã passa como se diz "sem intercorrências". 26 quimioterapias são realizadas, número este acima da média habitual, porém o que dizer sobre a humanização do serviço?

Humanizar seria olhar a paciente como ser singular que aí está em seu tempo e agora singular, e pode ter algo a dizer, pode querer partilhar aquele seu momento.

A quimioterapia é um tratamento sabidamente desgastante, física e emocionalmente. Mas neste dia, não há tempo para relacionamentos interpessoais. O tempo e a escala de serviço pressionam a equipe que perde a chance de enfocar a tarefa rotineira com um olhar mais humano, que pode gratificar pelo encontro que podemos ter com o outro ao compreendê-lo como vivendo um tempo único a cada dia, mesmo que pareçam iguais.

O tempo fenomenológico não é aquele tempo de minutos e segundos ao qual estamos habituados em nosso dia-a-dia, ou seja, o tempo cronológico que contamos no relógio, o tempo sempre igual no qual todos os dias têm 24 horas. $\mathrm{Na}$ situação descrita, a equipe de enfermagem está fechada no tempo cronológico, no agora do relógio, impossibilitada de perceber que cada agora é tempo singular, tempo engajado que tem a possibilidade de ser vivido autênticamente. Não parece haver entrosamento entre o profissional e a cliente para que seja perceptivel a existência desse tempo de engajamento com o vivido de cada instante, nem tão pouco há clareza, para o profissional, de seu próprio tempo de engajamento com as situações singulares vivenciadas a cada dia de sua atividade. Segundo o pensamento de Heidegger (1993 : 235), 
Esse encobrimento nivelador do tempo do mundo, realizado pela compreensão vulgar do tempo, não é acidental. Mas justamente porque a interpretação cotidiana do tempo se mantém unicamente na direção da visão da compreensibilidade das ocupaçôes...o agora, é compreendido conjuntamente na ocupação do que está à mão e do que é simplesmente dado.

Assim, segundo Simōes (1995:60), na cotidianidade, o tempo é público e está à disposição de todos igualmente e é interpretado de modo vulgar e como uma seqüência de agoras.

No seu fazer voltado para o relógio, a equipe de enfermagem e as pacientes, que entram e saem também ligadas ao cronológico do tempo vivido, não percebem a singularidade de cada momento e é assim que, para Heidegger (1993:134), apenas

Na medida em que a pre-sença se volta para o tempo compreendido e o "observa", ela vê os agoras que, de algum modo, estão "pre-sentes", no horizonte da compreensão ontológica, que, continuamente, orienta essa ocupação.

\section{Situação número 3}

A auxiliar de enfermagem diz para a enfermeira:

- Hoje não está dando! As pacientes estão muito nervosas, já entram chorando, irritadas, nervosas. Ficam conversando lá fora e entram cheias de medo. Já disse pra não ouvir conversa de corredor...

É comum, durante a espera e consulta para tratamento, que as pacientes conversem entre si. Nestas conversas surgem muitas opiniōes sobre a doença e o tratamento, casos por elas conhecidos como o tratamento que não surtiu efeito, a morte, enfim fatos e histórias tristes de outras mulheres.

Certamente muitos questionamentos devem surgir, assim como dúvidas, incertezas, quanto ao efeito positivo do tratamento, tristeza, desesperança entre outros. A paciente parece realmente nervosa após tanto falatório.

A equipe de enfermagem percebe isto, mas no seu hábito de estar ali ocupando-se da doença e do tratamento não se preocupa em se aproximar do outro e permitir o encontro com aquele ser-aí. O que consegue dizer é que conversa de corredor não é para ser levada em consideração, pois informação correta só quem pode dar é a equipe de saúde. A ela sim, a paciente deve ouvir.

Esquecem-se que ela não é apenas uma ouvinte, é um ser-aí que passa por um período dificil e que, enquanto pre-sença, está exposta ao falatório. Pode ter o que falar e questionar. Não estamos lidando com algo manual e sim com 
pessoas a quem devemos prestar cuidado. Cuidado este que envolve a humanização que torna a assistência de enfermagem efetiva.

A paciente, que está aguardando o atendimento para o tratamento, tem contato com as outras pacientes e nesse relacionar-se encontra-se exposta ao falatório. O falatório é um modo de ser da pre-sença a partir do qual ela realiza a compreensão e interpretação cotidiana. Ele se constitui pela falta de solidez, pois não está preocupado com uma apropriação originária do ente referencial, mas sim ocupa-se apenas em falar, em passar adiante a fala, sem fundamentá-la ou deter-se em sua compreensão originária. Para Heidegger (1995 :228),

Tanto a escuta quanto a compreensão já se colaram previamente no que foi falado no falatório. A comunicação não "partilha" a referência ontológica primordial com o ente referencial, mas a convivência se move dentro de uma fala comum e numa ocupação com o falado. $O$ seu empenho é que se fale.

O falatório constitui o modo de ser da pre-sença descompromissada consigo mesma e com os outros. Ele não eștá voltado para uma compreensão genuína e autêntica, segundo as possibilidades essenciais da pre-sença, de si mesma e dos entes que vêm ao encontro no mundo. Assim é que Heidegger (1995:230) pondera que,

...como ser no mundo, a pre-sença que se mantém no falatorio rasgou suas remissões ontológicas primordiais, originárias e legítimas com o mundo,com a co-presença e com o próprio ser-em. Ela se mantém oscilante e, desse modo, sempre é e está junto ao "mundo", com os outros e consigo mesma.

Estando na inautenticidade, a mulher que aguarda a quimioterapia, além de exposta ao falatório, deixa-se arrastar pela ambigüidade.Todo mundo sabe falar e prever o que acontecerá, muito embora a informação recebida pela equipe de saúde em nada coincida com o que se comenta no corredor. Para Heidegger (1995 :234),

Essa atitude de estar na pista e, na verdade, a partir do ouvir dizer quem autenticamente "está na pista"não fala sobre isso - é o modo mais traiçoeiro em que a ambigüidade propicia à pre-sença possibilidades, a fim de sufocar-Ihe a força.

\section{Situação número 4}

A enfermeira J. comenta que a paciente $X$., que hoje está iniciando o tratamento, está muito nervosa e chorando bastante. Ao aproximar-se para orientá-la quanto ao tratamento, deteve-se por mais algum tempo ao lado dela e pôde compreender, conforme conversavam, que a paciente estava com muitos 
problemas pessoais e estes, aliados ao tratamento, estavam deixando-a muito triste e tensa. Assim, a enfermeira relatou que, após ouvi-la, conversarem e trocarem idéias sobre o que parecia atormentar a paciente, esta referiu sentir-se mais calma e disposta a submeter-se ao tratamento.

Ao aproximar-se da paciente e permitir que ela falasse e não apenas dedicarse a orientá-la sobre o tratamento, a enfermeira pôde se permitir a um encontro com o outro. Possibilitou que o outro fosse ele mesmo de modo autêntico sem a impessoalidade tão comum no nosso dia-a-dia. $O$ encontro veio ainda permitir uma ação de enfermagem efetiva, já que não tratou apenas do aspecto funcionalista que se dá na nossa prática diária de cuidado.

A enfermeira, estando lançada no mundo e aberta na disposição da presença, deixou-se tocar pelo outro que veio a seu encontro e entregou-se à possibilidade originária de ser-no-mundo-com, de ser co-presença do outro.

A disposição é o que ôntica e cotidianamente conhecemos como humor. A pre-sença sempre está de humor, qualquer que ele seja. O humor sempre abre a pre-sença em seu pre, mesmo que ela não se dê conta ou disso se esquive. $\grave{A}$ esta abertura, que é um caráter ontológico da pre-sença, chamamos de estar lançado e significa a facticidade de ser entregue à responsabilidade. A disposição também apresenta um segundo caráter essencial para Heidegger (1995:191),

...ela é um modo existencial básico da abertura igualmente originária de mundo, de co-presença e existência, pois também este modo é em si mesmo ser-no-mundo.

Além de propiciar a abertura do estar-lançado e a abertura do ser-no-mundo, a disposição ainda proporciona à pre-sença uma compreensão mais profunda da mundanidade do mundo. Mundo este que, em sua abertura anterior, permite que o ente intramundano venha ao encontro, a partir da ocupação guiada pela circunvisão. Heidegger (1995 :191-92) nos diz que,

Numa ocupação dotada de circunvisão, deixar e fazer vir ao encontro tem o caráter de ser atingido... o ser-em como tal se acha determinado previamente em sua existência, de modo a poder ser tocado...pelo que vem ao encontro dentro do mundo.

Sendo tocada pelo outro que veio ao seu encontro dentro do mundo, a enfermeira partilha com a paciente seu ser-aí, realiza o encontro empático sendo-com ela. Para Heidegger (1995:177),

No ser-com e para os outros, subsiste, portanto, uma relação ontologica entre pre-senças. Essa relação, pode-se dizer, já é constitutiva de cada pre-sença própria, que possui por si mesma uma 
compreensão do ser $e$, assim, relaciona-se com a pre-sença. A relação ontológica com os outros torna-se,pois, projeção do ser-próprio para si mesmo "num outro".

\section{CONSIDERAÇÕES FINAIS}

A partir das reflexões iniciais que propiciaram este estudo e ao analisar as situações vivenciadas na prática diária de assistir segundo o pensamento heideggeriano, pude vislumbrar a assistência de enfermagem por uma outra ótica, aquela da compreensão como possibilidade do agir profissional. Compreensão esta que não significa apenas entender, notar ou explicar as necessidades fisiológicas emergentes da patologia e do tratamento da cliente, mas que nos permite, enquanto pre-sença que somos, estar junto ao outro como pessoa em sua totalidade, e não apenas junto a sua doença e/ou tratamento. Privilegiando o outro sim, como ser-ai e objeto de nosso cuidado enquanto profissionais de enfermagem, sem nos determos somente no problema físico que de imediato o aflige. Mas valorizando o exercício da empatia como forma de con-vivência autêntica, que nos dá e ao outro também, a oportunidade de ser-aícom.

A análise compreensiva mostrou que o profissional de enfermagem, submetido à pressão do tempo cronológico, preocupa-se com o quantitativo de atendimentos que deve realizar e com as tarefas a cumprir, e num movimento inautêntico ocupa-se da clientela.

Mostrou também como o falatório e a ambigüidade permeiam nosso dia-adia, desviando o ser de seu aí originário e mantendo-o descompromissado consigo mesmo, com os outros e portanto na inautenticidade.

No entanto, permitiu ainda perceber, que é possível em nosso cotidiano profissional, olhar o outro não como um ente e sim como pre-sença que somos, fazendo-se assim a abertura para a possibilidade de ser-com que nos permite con-viver autenticamente com o nosso semelhante.

Este estudo possibilitou ainda perceber que a enfermagem pode se beneficiar deste olhar diferente trazido pelo referencial fenomenológico, já que ele possibilita uma assistência holistica ao ver o outro não apenas como objeto do assistir mas sim como sujeito, que, sendo, merece um olhar de natureza compreensiva.

Além disso, cabe ressaltar que esta outra ótica pode projetar-se para o ensino e a pesquisa ao propiciar, tanto ao aluno como ao pesquisador de enfermagem, a liberdade de ser-ai com o cliente, voltando-se para o em si mesmo do assistir, sendo assim capaz de transformar a prática profissional. 


\section{BIBLIOGRAFIA}

1. BOEMER, Magali R.. Empatia - Proposta de Abordagem Fenomenológica. R. Esc. Enferm., USP, São Paulo, v. 18, n. 1 :23-9, 1984.

2. CAPALBO, Creusa. Considerações sobre o método fenomenológico e a enfermagem. R. Enferm. UERJ. Rio de Janeiro, v. 2, n. 2, out., 1994.

3. CAPALBO, Creusa. Abordando a enfermagem a partir da fenomenologia. R. Enferm. UERJ. Rio de Janeiro, v. 2, n. 1, maio 1994.

4. DARTIGUES, André. $O$ que é a Fenomenologia? 3. ed., São Paulo: Editora Moraes, $1992,174 \mathrm{p}$.

5. HEIDEGgER, Martin. Ser e Tempo - Parte I. 5. ed. Trad. Márcia de Sá Cavalcanti. Petrópolis: Vozes,1995, 325p.(Coleção Pensamento Humano).

6. Ser e Tempo - Parte II. $3^{\mathrm{a}}$ ed. Trad. Márcia de Sá Cavalcanti. Petrópolis: Vozes,1993, 262 p. (Coleção Pensamento Humano).

7. Todos nós... ninguém. Trad. Dulce Mara Critelli. São Paulo: Editora Moraes, 1981, 72p.

8. LOPES, Regina L. M. et al - A fenomenologia e a pesquisa em enfermagem. R. Enferm. UERJ. Rio de Janeiro, v. 3, n. 1, maio, 1995.

9. MARTINS, Joel, et al - A Fenomenologia como Alternativa Metodológica para Pesquisa - Algumas Consideraçōes. Mimeo, s.d.

10. SIMÕES, Sonia M. F. - O Ser Parturiente: Um Enfoque Vivencial. Dissertação. (Mestrado em Enfermagem) Escola de Enfermagem Anna Nery, UFRJ, Rio de Janeiro, 1995, 94p. 